\title{
Botulinum neurotoxin type $A$ for the treatment of pain: not just in migraine and trigeminal neuralgia
}

\author{
Giorgio Sandrini ${ }^{1,2}$, Roberto De Icco ${ }^{1,2}$, Cristina Tassorelli, ${ }^{1,2}$, Nicola Smania ${ }^{3,4}$ and Stefano Tamburin ${ }^{3^{*}}$ (D)
}

\begin{abstract}
Background: Despite their huge epidemiological impact, primary headaches, trigeminal neuralgia and other chronic pain conditions still receive suboptimal medical approach, even in developed countries. The limited efficacy of current pain-killers and prophylactic treatments stands among the main reasons for this phenomenon. Botulinum neurotoxin (BoNT) represents a well-established and licensed treatment for chronic migraine, but also an emerging treatment for other types of primary headache, trigeminal neuralgia, neuropathic pain, and an increasing number of pain conditions.

Methods: We searched and critically reviewed evidence for the efficacy of BoNT for the treatment of chronic pain.

Results: Meta-analyses and randomized controlled trials (RCTs) suggest that BoNT potentially represents a multi-purpose drug for the treatment of pain in several disorders due to a favorable safety profile and a long-lasting relief after a single injection.
\end{abstract}

Conclusions: BoNT is an emerging treatment in different pain conditions. Future RCTs should explore the use of BoNT injection therapy combined with systemic drugs and/or physical therapies as new pain treatment strategies.

Keywords: Botulinum neurotoxin, Primary headaches, Migraine, Neuropathic pain, Pain, Trigeminal neuralgia, Treatment

\section{Review}

Introduction

The prevalence of moderate-to-severe chronic non-cancer pain in Europe is estimated to be 20\% [1]. A large population-based study on the prevalence of primary headache $(\mathrm{PH})$ disorders in Germany estimated that 2.6\% of the general population suffer from headache $\geq 15$ days/ month, and $1.1 \%$ from chronic migraine [2]. Medicationoveruse headache $(\mathrm{MOH})$, i.e., chronic headache resulting from excessive consumption of pain-killers for headache, has an estimated worldwide prevalence of $0.5-7.2 \%$ [3]. Around $7 \%$ in the general population suffer from some form of chronic neuropathic pain (NP) [4].

The social and economic burden of chronic pain is staggering, in that it interferes with everyday activities, lowers productivity, affects personal relationships, and results in depressive symptoms. WHO ranks migraine as

\footnotetext{
* Correspondence: stefano.tamburin@univr.it

${ }^{3}$ Department of Neurosciences, Biomedicine and Movement Sciences,

University of Verona, Piazzale Scuro 10, I-37134 Verona, Italy

Full list of author information is available at the end of the article
}

the sixth highest cause of disability worldwide when considered alone, and the third highest when $\mathrm{MOH}$ is included [5]. According to U.S. figures, the total annual median cost for medical services and analgesics for the relief of migraine, low back pain, and fibromyalgia is roughly $\$ 5,000$ and more than $\$ 25,000$ for treating HIVrelated pain and multiple sclerosis [6]. Though lower than the estimated $\$ 50,000$ spent for ameliorating cancer pain [6], the toll that persistent pain and $\mathrm{PH}$ take on overall wellbeing is heavier because of the chronic course of the underlying condition.

Most patients with PH and chronic pain do not receive satisfactory treatment. A European survey reported that $43-81 \%$ of patients with headache were not satisfied with their treatment, and the main reason was poor effectiveness of prescribed drugs [7]. Around $25-50 \%$ of patients with trigeminal neuralgia (TN) become refractory to drug therapy, and surgical procedures are not always feasible in these patients, and they may occasionally result in severe complications [8]. Only 30-40\% of patients with NP achieve a $\geq 50 \%$ pain reduction with currently available 
therapies [9]. In a recent meta-analysis that took into account publication bias for negative studies, the Special Interest Group on Neuropathic Pain (NeuPSIG) of the International Association for the Study of Pain found that the number-needed-to-treat (NNT) for first-line NP drugs is 3.6-7.7, indicating that less than $30 \%$ of patients are responders, and the figures for other treatments are even worse [10]. The number-needed-to-harm (NNH) for these drugs ranges from 11.8 to 31.9 , resulting in high drop-out rates [10]. Non-opioid analgesics, nonsteroidal anti-inflammatory drugs, cyclooxygenase-2 inhibitors, and opioids are widely used for relieving nociceptive pain; however, following increased reports of adverse events and side effects, recent warnings and guidelines have been issued, advising caution when prescribing them [11]. Because current pharmacological approaches to $\mathrm{PH}, \mathrm{TN}, \mathrm{NP}$ and other types of chronic pain are inadequate and subject to unintentional abuse, alternative treatment options need to be reconsidered.

Botulinum neurotoxin (BoNT), a potent natural toxin produced by the anaerobic bacterium Clostridium botulinum, blocks the release of acetylcholine at the neuromuscular junction by inhibiting the soluble $\mathrm{N}$-ethylmaleimide-sensitive factor attachment protein receptor (SNARE) complex. Since the use of BoNT for the treatment of strabismus was pioneered more than 40 years ago, the therapeutic indications for BoNT type A (BoNT-A) and, more recently, type B for treating excessive and/or undesired muscle tone, have progressively expanded [12]. Currently available BoNT formulations, i.e., abobotulinumtoxin-A (Dysport; Ipsen, Paris, France), incobotulinumtoxin-A (Xeomin, Merz Pharmaceuticals GmbH, Frankfurt, Germany), onabotulinumtoxin-A (Botox; Allergan, Inc., Irvine, CA, USA), and rimabotulinumtoxin-B (Myobloc/Neurobloc; Solstice Neurosciences, Inc., San Francisco, CA, USA) are licensed for the treatment of spasticity and dystonia, and were applied in 17 million treatments between 1994 and 2013 in the United States alone [12]. Though the formulations differ in pharmacological profile, potency, dosage, and approved indications, BoNT is recognized as a safe and effective treatment for spasticity resulting from stroke, multiple sclerosis and spinal cord injury, as well as for dystonia, tremor, and other movement disorders [12]. Guidelines and expert opinions derived from broadbased, high-quality evidence recommend the use of BoNT either alone or in combination with rehabilitation procedures as first-line treatment for spasticity and focal dystonia [13-15].

Not surprisingly, BoNT was found to reduce pain in spasticity, dystonia, and related conditions where pain reduction is an important outcome [13, 14]. Serendipitous clinical observations that pain symptoms may improve independently of muscle hyperactivity and with a different time course after BoNT injection have spurred the exploration of the mechanisms underlying this effect in animal models and the collection of evidence in clinical settings [16]. Animal models indicate that BoNT may be effective in controlling pain via its interaction with the SNARE complex that blocks synaptic vesicle fusion and inhibits the release of various pain-modulating neurotransmitters, including glutamate, substance $\mathrm{P}$, calcitonin gene-related peptide, and pain-sensing transmembrane receptors, such as transient receptor potential channels on the neuronal plasma membrane [16]. In addition, growing evidence suggests that the analgesic and anti-inflammatory effects of BoNT are mediated through various molecular pathways in both the peripheral nerves and the spinal cord [16]. Figure 1 summarizes the neurobiological mechanisms through which BoNT may modulate pain, and their possible anatomical levels.

Here we reviewed published evidence on the use of BoNT for the treatment of pain. Since a number of meta-analyses have already been published on this topic, we chose a narrative approach, focusing more specifically on a critical review of current data and possible future approaches.

\section{Methods}

The electronic database MEDLINE (accessed by Pubmed; 1 January 2006-31 December 2016) was searched with the string (("pain" [MeSH Terms] OR "pain" [All Fields]) AND ("botulinum toxins" [MeSH Terms] OR ("botulinum" [All Fields] AND "toxins" [All Fields]) OR "botulinum toxins" [All Fields] OR ("botulinum" [All Fields] AND "toxin" [All Fields]) OR "botulinum toxin" [All Fields])) AND (Clinical Trial[ptyp] OR ("meta-analysis" [Publication Type] OR "meta-analysis as topic" [MeSH Terms] OR "meta-analysis" [All Fields])) with no language restrictions and all the titles and abstracts identified by the search were evaluated for eligibility.

\section{Results}

The PubMed searched yielded 84 randomized controlled trials (RCTs) and 36 meta-analyses or systematic reviews, indicating a consistent bulk of data on the role of BoNT-A for the treatment of chronic pain. The conditions for which at least one meta-analysis was available are summarized in Table 1.

Based on the PREEMPT program that included data from two multicenter RCTs ( $n=1384$ patients), BoNT-A was given regulatory approval for the treatment of chronic migraine (CM) in 2010, the fact notwithstanding that its mechanism of action is not yet completely elucidated [17]. A meta-analysis on the role of BoNT as a prophylactic treatment of migraine showed that BoNT-A compared with placebo was associated with a 


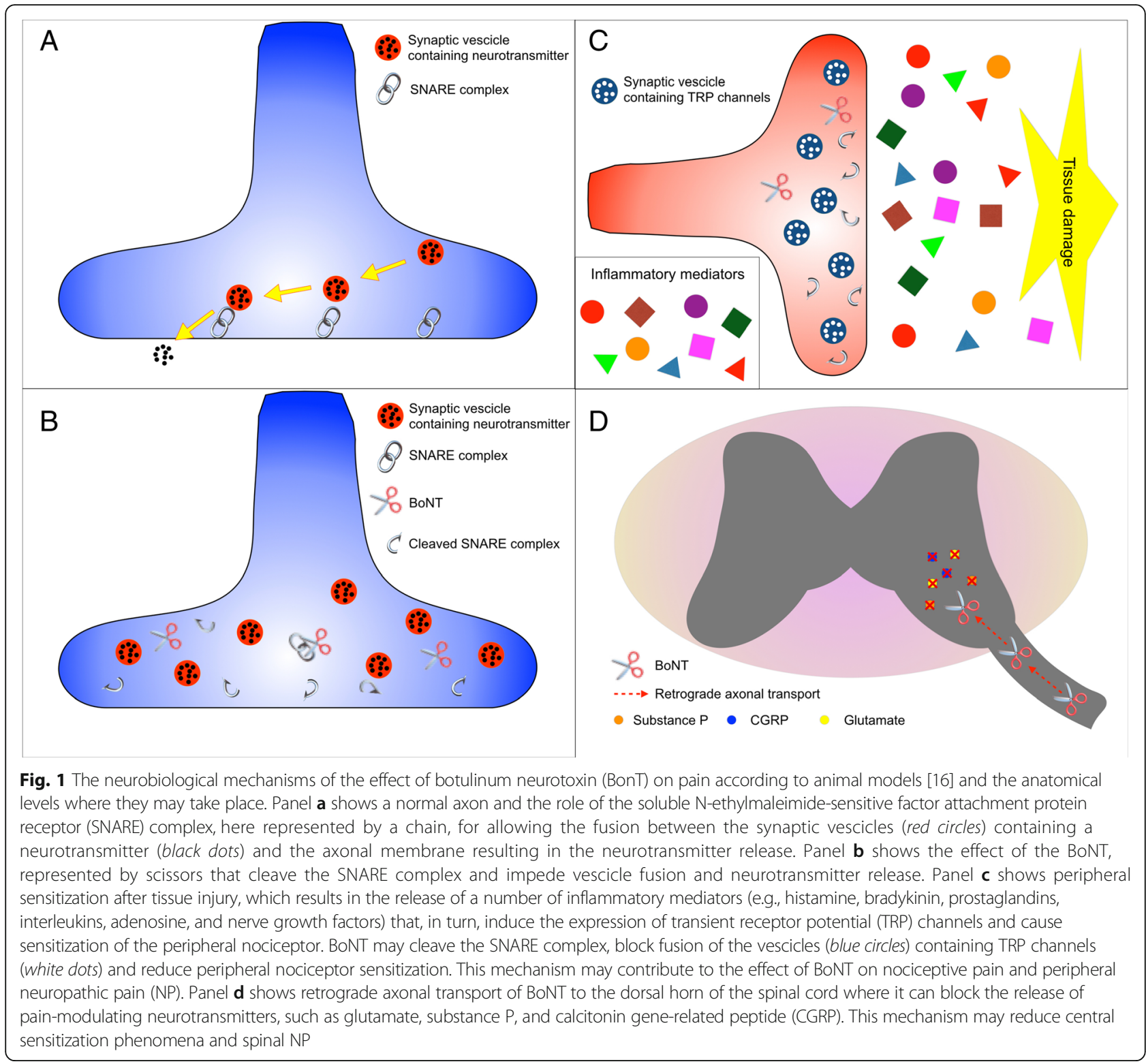

small-to-modest benefit for chronic daily headache and CM (i.e., a mean -2.1 to -2.3 reduction in headache episodes per months), but was not associated with fewer episodic migraine or chronic tension-type headaches (TTHs) per month [18]. A RCT on the treatment of $\mathrm{MOH}$ failed to document an effect on the headache days, but showed a reduction of drug consumption [19]. Overall, BoNT adverse events were few and not serious in CM patients [20].

Open-label data suggest that intramuscular injection of BoNT-A in the masseter muscle may improve pain in patients with temporomandibular disorders (TMD) and TTH [21]. Systematic reviews on TMD reported significant myofascial pain reduction following BoNT treatment in comparison to placebo in two RCTs, no significant difference in two RCTs, and equal efficacy of BoNT and fascial manipulation in one RCT, but a meta-analysis was not possible because of considerable variations in study design and outcomes [22].

Five high quality RCTs indicated little or no effect of BoNT-A, and two very low quality RCTs suggested little or no difference between BoNT-A and placebo, both combined with physiotherapeutic exercise and analgesics, in patients with chronic neck pain [23]. A very low quality RCT showed little or no effect of BoNT-A in chronic cervicogenic headache [23]. Three RCTs showed no effect of BoNT-A in pain related to whiplash injury [24].

A recently published meta-analysis concluded that BoNT-A may be an effective and safe treatment option for patients with $\mathrm{TN}$, in that it yielded, on average, a 
Table 1 Evidence for the use of BoNT-A in chronic pain conditions

\begin{tabular}{|c|c|c|c|c|c|}
\hline Condition & Subjects & Studies & Comparator & Outcome $^{a}$ & Ref \\
\hline EM & 1838 & 9 & Placebo & n.s. & 18 \\
\hline \multirow[t]{3}{*}{ CM } & 1508 & 5 & Placebo & HEPM: $-2.30[95 \% \mathrm{Cl}:-3.7,-0.9]$ & 18 \\
\hline & 59 & 1 & Topiramate & n.s. & 18 \\
\hline & 72 & 1 & Amitriptyline & n.s. & 18 \\
\hline $\mathrm{CDH}$ & 1115 & 1 & Placebo & HEPM: $-2.1[95 \% \mathrm{Cl}:-3.6,-0.6]$ & 18 \\
\hline \multirow[t]{2}{*}{ Any TTH } & 59 & 1 & Valproate & n.s. & 18 \\
\hline & 21 & 1 & Steroids & HEPM: $-2.5[95 \%$ Cl:-3.5, -1.5] & 18 \\
\hline Chronic TTH & 675 & 7 & Placebo & n.s. & 18 \\
\hline \multirow[t]{2}{*}{ TMD } & 145 & 4 & Placebo & Meta-analysis not performed & 22 \\
\hline & 30 & 1 & Manipulation & n.s. & 22 \\
\hline$C N P^{b}$ & 371 & 8 & Placebo & Little or no difference & 23 \\
\hline $\mathrm{CCH}$ & 32 & 1 & Placebo & Little or no difference & 23 \\
\hline Whiplash & 96 & 3 & Placebo & n.s. & 24 \\
\hline TN & 178 & 4 & Placebo & PPD: -29.8 [95\% Cl:-38.5, -21.1] & 8 \\
\hline Diabetic NP & 76 & 2 & Placebo & 0-10 VAS: -2.0 [95\% Cl:-3.1, -0.8] & 27 \\
\hline Peripheral NP & 68 & 1 & Placebo & 0-10 NRS:-0.8 [95\% Cl:-1.0, -0.6] & 26 \\
\hline Spinal NP & 40 & 1 & Placebo & Significant VAS reduction & 28 \\
\hline Myofascial & 332 & 8 & Placebo & n.s. & 24 \\
\hline PSSP & 86 & 5 & Placebo & 0-10 VAS: $-1.2[95 \% \mathrm{Cl}:-2.4,-0.1]$ & 29 \\
\hline ASP & 40 & 1 & Placebo & $0-10$ VAS $-2.0[95 \% \mathrm{Cl}:-3.7,-0.3]$ & 29 \\
\hline LE & 274 & 4 & Placebo & ES: $-0.5[95 \%$ Cl:-0.9, -0.1$]$ & 31 \\
\hline LBP & 131 & 3 & Mixed $^{c}$ & Meta-analysis not performed & 33 \\
\hline Ankle OA & 75 & 1 & $\mathrm{HA}$ & n.s. & 34 \\
\hline \multirow[t]{2}{*}{ PF } & 133 & 3 & Placebo & n.s. & 35 \\
\hline & 136 & 2 & Steroids & Pain relief: $-0.7[95 \% \mathrm{Cl}:-1.0,-0.3]$ & 35 \\
\hline BPS & 317 & 6 & Placebo & 0-10 VAS -1.7 [95\% Cl:-3.2, -0.3] & 38 \\
\hline
\end{tabular}

Here are reported chronic pain conditions for which at least one meta-analysis or systematic review was available. ASP Arthritic shoulder pain, BoNT-A Botulinum neurotoxin type A, BPS Bladder pain syndrome, $C C H$ Chronic cervicogenic headache, $C D H$ Chronic daily headache, $C I C o n f i d e n c e$ interval, $C M$ Chronic migraine, CNP Chronic neck pain, EM Episodic migraine, ES Effect size, HA Hyaluronic acid, HEPM Headache episodes per months, LBP Low back pain, LE Lateral epycondylitis, NP Neuropathic pain, NRS Numerical rating scale, n.s. Not significant, OA Osteoarthritis, PF Plantar fasciitis, PPD Paroxysms per day, PSSP Post-stroke shoulder pain, TMD Temporomandibular disorders, TN Trigeminal neuralgia, TTH Tension type headache, VAS Visual analogue scale

${ }^{a}$ Results of the comparison between BoNT and comparator

${ }^{b}$ Physiotherapeutic exercise and analgesics were combined with both BoNT and placebo in two studies ( $n=95$ patients)

'Placebo, acupuncture or steroids

-29.8 reduction in paroxysms per day [8]. Conversely, BoNT was not found to be effective in occipital neuralgia [25].

RCTs have documented that BoNT-A may be effective in peripheral NP, including painful diabetic neuropathy, post-herpetic and post-traumatic neuralgia [26]. A meta-analysis including two studies on diabetic NP showed a -2.0 reduction on a $0-10$ visual analogue scale (VAS) following treatment with BoNT-A, resulting in clinically significant improvement of minimum change in pain, with no more adverse effects than placebo [27]. A RCT on peripheral NP documented a -0.8 reduction in numerical rating scale over 24 weeks compared with placebo [26]. A RCT on NP secondary to spinal cord injury showed significant reduction at 4 weeks (active:
$18.6 \pm 16.8$; placebo: $2.6 \pm 14.6$ ) and 8 weeks (active: 21.3 \pm 26.8 ; placebo: $0.3 \pm 19.5$ ) after BoNT-A [28]. The NeuPSIG recommended BoNT-A as third line pharmacological treatment for NP, assigning it the same strength of recommendation as strong opioids [10]. This recommendation was largely based on the high tolerability of BoNT-A and the safety concerns related to opioids, despite the fact that effectiveness and the bulk of evidence favoring opioids, particularly oxycodone and morphine, is far more robust [10].

Eight RCTs documented no significant effect of BoNT-A in myofascial pain syndrome [24].

Studies with a small sample size and a high risk of bias have suggested that intramuscular BoNT-A injection may reduce pain (i.e., on average between -1.2 and -2.0 
points on a $0-10$ VAS) and improve function in chronic shoulder pain from spastic hemiplegia or arthritis [29]. A similar effect was documented after intra-articular BoNT-A injection for refractory hemiplegic shoulder pain [30].

Four RCTs documented a moderate effect on pain to BoNT-A $60 \mathrm{U}$ injection into the forearm extensor muscles in chronic treatment-resistant lateral epicondylitis [31]. A recent Bayesian network meta-analysis that compared different injection therapies for lateral epicondylitis showed a not significant trend towards better effect than placebo for BoNT-A [32].

Three RCTs showed that BoNT-A improves pain, function, or both better than saline injections, acupuncture or steroid injections in patients with low back pain and sciatica, but the low-quality and heterogeneity of studies impeded a meta-analysis [33].

A RCT on ankle osteoarthritis reported no significant difference between BoNT and hyaluronic acid, which in turn appeared not more effective than exercise therapy, and did not seem to offer clinically relevant advantage in comparison to placebo [34]. Data from three RCTs documented no significant difference between BoNT-A and placebo, and those from two RCTs showed slight significant advantage of BoNT-A over corticosteroids in plantar fasciitis, but a network meta-analysys including 22 RCTs indicated BoNT-A as the most likely treatment to relieve pain in this condition [35].

Limited evidence of efficacy for peripheral BoNT injection therapy for residual limb pain after amputation is suggested by very small trials and case series, while a small RCT showed that BoNT-A was not superior to lidocaine and methylprednisolone in this condition [36].

Pelvic pain, also known as bladder pain syndrome (BPS) or interstitial cystitis, is a complex condition with an ill-defined pathogenesis [37]. Six RCTs showed that intravesical BoNT-A injections might offer significant improvement in pain (i.e., average -1.7 points reduction on a $0-10$ VAS), daytime urination frequency, and maximum cystometric capacity for patients with refractory BPS [38].

BoNT-A was found to improve post-surgical and postradiation pain in cancer patients in a small open-label study [39].

\section{Discussion and conclusions}

The current evidence reviewed here indicate that BoNT-A represents an effective prophylactic treatment for $\mathrm{CM}$, and may be helpful in other types of cranial, facial, and cervical pain, as well as in patients with $\mathrm{TN}$, peripheral and spinal NP, some types of pain secondary to musculoskeletal diseases, and BPS. For most of these conditions, however, the quality of evidence is low, and the sample size of RCTs is small. In some conditions, such as NP, where the evidence for first-line treatments (i.e., $\alpha_{2}-\delta$ ligands, antidepressants) comes from a consistently larger number of patients, evidence supporting the use of BoNT should be considered with caution and preliminary.

Neurobiological grounds for the use of BoNT in pain come from experimental models [16]. Despite the heterogeneity of conditions, routes of administration, and outcomes, studies that sought to identify bestresponder profiles suggest that complete denervation or nerve transection predicts poor pain response to BoNT [26, 28]. This clinical observation is in keeping with animal models that indicate that the analgesic effect of BoNT is mediated, at least in part, by retrograde axonal transport to the spinal cord [16].

According to the International Classification of Headache Disorders, the essential diagnostic criteria of $\mathrm{PH}$ disorders are based on the presence of specific clinical features and the absence of decisive pathological or radiological findings. It is noteworthy that the classification of a patient in a given $\mathrm{PH}$ subtype may change in a quarter of cases, especially when the diagnosis is probable, even in expert centers [40]. Patients suffering from chronic migraine frequently report other types of pain (i.e., fibromyalgia), and both types of pain are usually more or less refractory to common treatments [41].

Identifying different types of pain (e.g., neuropathic, osteoarticular, or associated with excessive muscle tone) in the same patient represents the first step towards developing a more appropriate and mechanisms-based pharmacological prescription for pain [11]. Guidelines and diagnostic algorithms for the management of NP may be difficult to apply in clinical conditions such as low back pain, for example, where different types of pain coexist [42]. While stratification of NP patients by their underlying sensory profile has been suggested to better inform the design of RCTs and personalized pharmacological treatment, the clinical utility of this tempting approach has not yielded more favorable NNT-NNH profiles for NP drugs [9]. Clinical scenarios are more complex and 'real-world' patients are very different from those enrolled in RCTs. Diagnosis of NP according to the NeuPSIG diagnostic algorithm has many merits, including different levels of certainty (i.e., probable, possible, definite), but it requires a solid knowledge of central and peripheral nervous system anatomy that not all pain physicians may possess [42]. The elderly and neurological patients may have several comorbidities and cognitive impairments that can blur the clinical expression of pain. Furthermore, thorough examination to evaluate the different types of pain may not be possible due to time constrictions in some cases.

BoNT-A was found to be effective for relieving PH, $\mathrm{TN}, \mathrm{NP}$, nociceptive and osteoarticular pain, as well as pain symptoms associated with muscle hypertonus. Its 
effect on different pain mechanisms coexisting in the same patient, together with its favorable side effect profile and long-lasting pain relief after a single injection, when effective, make BoNT-A a potential multi-purpose drug for pain treatment in a variety of neurological and non-neurological conditions. There are, however, several open questions that warrant further studies.

PREEMPT data showed a mean reduction of approximately 2 headache days out of 4 weeks after BoNT-A in comparison to placebo in chronic migraine patients [17]. Similarly, in many RCTs, self-rated pain reduction after BoNT-A injection was generally no more than 2 points on a visual analogue or numerical rating scale from 0 to $10[26,28,29]$, which is insufficient to document a satisfactory response in most patients. The association of an ad hoc rehabilitative program was found to improve the clinical efficacy of BoNT in cervical dystonia [43]. A future area of focus for RCTs should be to explore the potential role of BoNT injection therapy in combination with systemic drugs and/or physical therapies.

Furthermore, BoNT was found to be effective on pain through various routes of injection, including subcutaneous, intramuscular, and intraarticular ones. A small RCT showed that BoNT-A profoundly prolonged (i.e., 2 months on average) analgesia after bupivacaine sympathetic blocks in patients with complex regional pain syndrome, a devastating pain conditions with no established treatment [44]. Comparison of different routes of injection might offer new pieces of information for optimizing the use of BoNT for the treatment of pain.

The most appropriate BoNT dosage is still unknown. In $\mathrm{MOH}$, onabotulinumtoxin-A $100 \mathrm{U}$ was found to be ineffective on the headache days in a RCT [19], while an open label prospective study that evaluated two doses of onabotulinumtoxin-A (i.e., $155 \mathrm{U}$ and $195 \mathrm{U}$ ) reported a significant reduction of the number of headache and migraine days for both doses, but with a superiority of the higher dosage [45]. These data suggest that dose-finding studies may represent another promising field of research.

\section{Abbreviations}

BoNT: Botulinum neurotoxin; BoNT-A: Botulinum neurotoxin type A

CM: Chronic migraine; MOH: Medication-overuse headache; NeuPSIG: Special Interest Group on Neuropathic Pain; NNH: Number-needed-to-harm; NNT: Number-needed-to-treat; NP: Neuropathic pain; PH: Primary headache; RCT: Randomized controlled trial; SNARE: Soluble N-ethylmaleimide-sensitive factor attachment protein receptor; TMD: Temporomandibular disorders; TN: Trigeminal neuralgia; TTH: Tension-type headache

\section{Acknowledgments}

None.

\section{Funding}

None.

\section{Authors' contributions}

GS, RDI and ST contributed to the conception and design of the study. All authors contributed to the collection of data. RDI and ST drafted the manuscript, which was critically reviewed for important intellectual content by all authors. All authors approved the final version of the manuscript.

\section{Competing interests}

GS received unconditioned research grants from Allergan and Merz, he was advisor for Abbott and Allergan, and served as speaker for Allergan. RDI declares no competing interest. CT participated to advisory boards for Allergan, Autonomic Technologies and ElectroCore, and received research support from Helsinn, Indena and MSD. NS participated to advisory boards for Allergan, Ipsen and Merz Pharma. ST participated to advisory boards for Abbvie, Epitech Group and Mundipharma, received honoraria from Allergan and Grünenthal, and research support from CSL Behring, Grünenthal, and Pfizer.

\section{Publisher's Note}

Springer Nature remains neutral with regard to jurisdictional claims in published maps and institutional affiliations.

\section{Author details}

${ }^{1}$ C. Mondino National Institute of Neurology Foundation, IRCCS, Pavia, Italy. ${ }^{2}$ Department of Brain and Behavioural Sciences, University of Pavia, Pavia, Italy. ${ }^{3}$ Department of Neurosciences, Biomedicine and Movement Sciences, University of Verona, Piazzale Scuro 10, I-37134 Verona, Italy. ${ }^{4}$ Neuromotor and Cognitive Rehabilitation Research Centre, University of Verona, Verona, Italy.

Received: 17 January 2017 Accepted: 10 March 2017

Published online: 21 March 2017

\section{References}

1. Reid KJ, Harker J, Bala MM, Truyers C, Kellen E, Bekkering GE, Kleijnen J (2011) Epidemiology of chronic non-cancer pain in Europe: narrative review of prevalence, pain treatments and pain impact. Curr Med Res Opin 27:449-62

2. Yoon MS, Katsarava Z, Obermann M, Fritsche G, Oezyurt M, Kaesewinkel K, Katsarova A, Santowski I, Diener H, Moebus S (2012) Prevalence of primary headaches in Germany: results of the German Headache Consortium Study. J Headache Pain 13:215-23

3. Giamberardino MA, Mitsikostas DD, Martelletti P (2015) Update on Medication-Overuse Headache and Its Treatment. Curr Treat Options Neurol 17:368

4. Bouhassira D, Lanteri-Minet M, Attal N, Laurent B, Touboul C (2008) Prevalence of chronic pain with neuropathic characteristics in the general population. Pain 136:380-7

5. Negro A, Curto M, Lionetto L, Giamberardino MA, Martelletti P (2016) Chronic migraine treatment: from OnabotulinumtoxinA onwards. Expert Rev Neurother 16:1217-27

6. Davis JA, Robinson RL, Le TK, Xie J (2011) Incidence and impact of pain conditions and comorbid illnesses. J Pain Res 4:331-45

7. Tassorelli C, Farm I, Kettinen H, de la Torre ER, Stretenovic S, Thomas W, Vriezen P, Van Os L, Krause D, Craven A (2014) Access to care-an unmet need in headache management? J Headache Pain 15:20

8. Morra ME, Elgebaly A, Elmaraezy A, Khalil AM, Altibi AM, Vu TL, Mostafa MR, Huy NT, Hirayama K (2016) Therapeutic efficacy and safety of Botulinum Toxin A Therapy in Trigeminal Neuralgia: a systematic review and meta-analysis of randomized controlled trials. J Headache Pain 17:63

9. Magrinelli F, Zanette G, Tamburin S (2013) Neuropathic pain: Diagnosis and treatment. Pract Neurol 13:292-307

10. Finnerup NB, Attal N, Haroutounian S, McNicol E, Baron R, Dworkin RH, Gilron I, Haanpää M, Hansson P, Jensen TS, Kamerman PR, Lund K, Moore A Raja SN, Rice AS, Rowbotham M, Sena E, Siddall P, Smith BH, Wallace M (2015) Pharmacotherapy for neuropathic pain in adults: a systematic review and meta-analysis. Lancet Neurol 14:162-73

11. Tamburin S, Lacerenza MR, Castelnuovo G, Agostini M, Paolucci S, Bartolo M, Bonazza S, Federico A, Formaglio F, Giusti EM, Manzoni GM, Mezzarobba S, Pietrabissa G, Polli A, Turolla A, Sandrini G, ICCPN (2016) Pharmacological and non-pharmacological strategies in the integrated treatment of pain in neurorehabilitation. Evidence and recommendations from the Italian Consensus Conference on Pain in Neurorehabilitation. Eur J Phys Rehabil Med 52:741-52

12. Abrams SB, Hallett M (2013) Clinical utility of different botulinum neurotoxin preparations. Toxicon 67:81-6 
13. Paolucci S, Martinuzzi A, Scivoletto G, Smania N, Solaro C, Aprile I, Armando M, Bergamaschi R, Berra E, Berto G, Carraro E, Cella M, Gandolfi M, Masciullo M, Molinari M, Pagliano E, Pecchioli C, Roncari L, Torre M, Trabucco E, Vallies G, Zerbinati P, Tamburin S, ICCPN (2016) Assessing and treating pain associated with stroke, multiple sclerosis, cerebral palsy, spinal cord injury and spasticity. Evidence and recommendations from the Italian Consensus conference on Pain in Neurorehabilitation. Eur J Phys Rehabil Med 52:827-40

14. Bartolo M, Chiò A, Ferrari S, Tassorelli C, Tamburin S, Avenali M, Azicnuda E, Calvo A, Caraceni AT, Defazio G, De Icco R, Formisano R, Franzoni S, Greco E, Jedrychowska I, Magrinelli F, Manera U, Marchioni E, Mariotto S, Monaco S, Pace A, Saviola D, Springhetti I, Tinazzi M, De Tanti A, ICCPN (2016) Assessing and treating pain in movement disorders, amyotrophic lateral sclerosis, severe acquired brain injury, disorders of consciousness, dementia, oncology and neuroinfectivology. Evidence and recommendations from the Italian Consensus Conference on Pain in Neurorehabilitation. Eur J Phys Rehabil Med 52:841-54

15. Simpson DM, Hallett M, Ashman EJ, Comella CL, Green MW, Gronseth GS, Armstrong MJ, Gloss D, Potrebic S, Jankovic J, Karp BP, Naumann M, So YT, Yablon SA (2016) Practice guideline update summary: Botulinum neurotoxin for the treatment of blepharospasm, cervical dystonia, adult spasticity, and headache: Report of the Guideline Development Subcommittee of the American Academy of Neurology. Neurology 86:1818-26

16. Kim DW, Lee SK, Ahnn J (2015) Botulinum Toxin as a Pain Killer: Players and Actions in Antinociception. Toxins 7:2435-53

17. Aurora SK, Winner P, Freeman MC, Spierings EL, Heiring JO, DeGryse RE, VanDenburgh AM, Nolan ME, Turkel CC (2011) OnabotulinumtoxinA for treatment of chronic migraine: pooled analyses of the 56-week PREEMPT clinical program. Headache 51:1358-73

18. Jackson JL, Kuriyama A, Hayashino Y (2012) Botulinum toxin A for prophylactic treatment of migraine and tension headaches in adults: a meta-analysis. JAMA 307:1736-45

19. Sandrini G, Perrotta A, Tassorelli C, Torelli P, Brighina F, Sances G, Nappi G (2011) Botulinum toxin type-A in the prophylactic treatment of medication-overuse headache: a multicenter, double-blind, randomized, placebo-controlled, parallel group study. J Headache Pain 12:427-33

20. Vikelis M, Argyriou AA, Dermitzakis EV, Spingos KC, Mitsikostas DD (2016) Onabotulinumtoxin-A treatment in Greek patients with chronic migraine. J Headache Pain 17:84

21. Pihut M, Ferendiuk E, Szewczyk M, Kasprzyk K, Wieckiewicz M (2016) The efficiency of botulinum toxin type A for the treatment of masseter muscle pain in patients with temporomandibular joint dysfunction and tension-type headache. J Headache Pain 17:29

22. Chen YW, Chiu YW, Chen CY, Chuang SK (2015) Botulinum toxin therapy for temporomandibular joint disorders: a systematic review of randomized controlled trials. Int J Oral Maxillofac Surg 44:1018-26

23. Langevin P, Peloso PM, Lowcock J, Nolan M, Weber J, Gross A, Roberts J, Goldsmith CH, Graham N, Burnie SJ, Haines T (2011) Botulinum toxin for subacute/chronic neck pain. Cochrane Database Syst Rev 6:CD008626

24. Zhang T, Adatia A, Zarin W, Moitri M, Vijenthira A, Chu R, Thabane L, Kean W (2011) The efficacy of botulinum toxin type $A$ in managing chronic musculoskeletal pain: a systematic review and meta analysis. Inflammopharmacology 19:21-34

25. Oh HM, Chung ME (2015) Botulinum Toxin for Neuropathic Pain: A Review of the Literature. Toxins 7:3127-54

26. Attal N, de Andrade DC, Adam F, Ranoux D, Teixeira MJ, Galhardoni R, Raicher I, Üçeyler N, Sommer C, Bouhassira D (2016) Safety and efficacy of repeated injections of botulinum toxin $A$ in peripheral neuropathic pain (BOTNEP): a randomised, double-blind, placebo-controlled trial. Lancet Neurol 15:555-65

27. Lakhan SE, Velasco DN, Tepper D (2015) Botulinum Toxin-A for Painful Diabetic Neuropathy: A Meta-Analysis. Pain Med 16:1773-80

28. Han ZA, Song DH, Oh HM, Chung ME (2016) Botulinum toxin type A for neuropathic pain in patients with spinal cord injury. Ann Neurol 79:569-78

29. Singh JA, Fitzgerald PM (2010) Botulinum toxin for shoulder pain. Cochrane Database Syst Rev 9:CD008271

30. Castiglione A, Bagnato S, Boccagni C, Romano MC, Galardi G (2011) Efficacy of intra-articular injection of botulinum toxin type $A$ in refractory hemiplegic shoulder pain. Arch Phys Med Rehabil 92:1034-7

31. Kalichman L, Bannuru RR, Severin M, Harvey W (2011) Injection of botulinum toxin for treatment of chronic lateral epicondylitis: systematic review and meta-analysis. Semin Arthritis Rheum 40:532-8
32. Dong W, Goost H, Lin XB, Burger C, Paul C, Wang ZL, Kong FL, Welle K, Jiang ZC, Kabir K (2016) Injection therapies for lateral epicondylalgia: a systematic review and Bayesian network meta-analysis. Br J Sports Med 50:900-8

33. Waseem Z, Boulias C, Gordon A, Ismail F, Sheean G, Furlan AD (2011) Botulinum toxin injections for low-back pain and sciatica. Cochrane Database Syst Rev 1:CD008257

34. Witteveen AG, Hofstad CJ, Kerkhoffs GM (2015) Hyaluronic acid and other conservative treatment options for osteoarthritis of the ankle. Cochrane Database Syst Rev 17:CD010643

35. Tsikopoulos K, Vasiliadis HS, Mavridis D (2016) Injection therapies for plantar fasciopathy ('plantar fasciitis'): a systematic review and network meta-analysis of 22 randomised controlled trials. Br J Sports Med 50:1367-75

36. Alviar MJ, Hale T, Dungca M (2016) Pharmacologic interventions for treating phantom limb pain. Cochrane Database Syst Rev 10:CD006380

37. Picelli A, Buzzi MG, Cisari C, Gandolfi M, Porru D, Bonadiman S, Brugnera A, Carone R, Cerbo R, Del Carro U, Gimigliano R, Invernizzi M, Miotti D, Nappi R, Negrini S, Schweiger V, Tassorelli C, Tamburin S, ICCPN (2016) Headache, low back pain, other nociceptive and mixed pain conditions in neurorehabilitation. Evidence and recommendations from the Italian Consensus Conference on Pain in Neurorehabilitation. Eur J Phys Rehabil Med 52:867-80

38. Wang J, Wang Q, Wu Q, Chen Y, Wu P (2016) Intravesical Botulinum Toxin A Injections for Bladder Pain Syndrome/Interstitial Cystitis: A Systematic Review and Meta-Analysis of Controlled Studies. Med Sci Monit 22:3257-67

39. Rostami R, Mittal SO, Radmand R, Jabbari B (2016) Incobotulinum Toxin-A Improves Post-Surgical and Post-Radiation Pain in Cancer Patients. Toxins 8(1):E22

40. Kim BS, Moon HS, Sohn JH, Cha MJ, Song TJ, Kim JM, Park JW, Park KY, Cho SJ, Kim SK (2016) Short-term diagnostic stability of probable headache disorders based on the International Classification of Headache Disorders, 3rd edition beta version, in first-visit patients: a multicenter follow-up study. J Headache Pain 17:13

41. Giamberardino MA, Affaitati G, Martelletti P, Tana C, Negro A, Lapenna D, Curto M, Schiavone C, Stellin L, Cipollone F, Costantini R (2015) Impact of migraine on fibromyalgia symptoms. J Headache Pain 17:28

42. Porro CA, Sandrini G, Truini A, Tugnoli V, Alfonsi E, Berliocchi L, Cacciatori C, LA Cesa S, Magrinelli F, Sacerdote P, Valeriani M, Tamburin S (2016) Diagnosing and assessing pain in neurorehabilitation: from translational research to the clinical setting. Evidence and recommendations from the Italian Consensus conference on pain in neurorehabilitation. Eur J Phys Rehabil Med 52:717-29

43. Tassorelli C, Mancini F, Balloni L, Pacchetti C, Sandrini G, Nappi G, Martignoni E (2006) Botulinum toxin and neuromotor rehabilitation: An integrated approach to idiopathic cervical dystonia. Mov Disord 21:2240-3

44. Carroll I, Clark JD, Mackey S (2009) Sympathetic block with botulinum toxin to treat complex regional pain syndrome. Ann Neurol 65:348-51

45. Negro A, Curto M, Lionetto L, Martelletti P (2015) A 2 years open-label prospective study of OnabotulinumtoxinA $195 \mathrm{U}$ in medication overuse headache: a real-world experience. J Headache Pain 17:1

\section{Submit your manuscript to a SpringerOpen ${ }^{\circ}$ journal and benefit from:}

- Convenient online submission

- Rigorous peer review

- Immediate publication on acceptance

- Open access: articles freely available online

- High visibility within the field

- Retaining the copyright to your article

Submit your next manuscript at springeropen.com 